OPEN ACCESS

Edited by:

Adriana Castello Costa Girardi, University of São Paulo, Brazil

Reviewed by: Matteo Parotto,

University of Toronto, Canada John T. Fisher,

Queen's University, Canada

*Correspondence: Bruno Chenuel b.chenuel@chru-nancy.fr

Specialty section:

This article was submitted to Respiratory Physiology, a section of the journal Frontiers in Physiology

Received: 09 October 2020 Accepted: 29 December 2020 Published: 18 February 2021

Citation:

Allado E, Poussel M, Valentin S, Kimmoun A, Levy B, Nguyen DT, Rumeau $C$ and Chenuel B (2021) The

Fundamentals of Respiratory Physiology to Manage the COVID-19 Pandemic: An Overview.

Front. Physiol. 11:615690. doi: 10.3389/fphys.2020.615690

\section{The Fundamentals of Respiratory Physiology to Manage the COVID-19 Pandemic: An Overview}

\author{
Edem Allado ${ }^{1,2}$, Mathias Poussel ${ }^{1,2}$, Simon Valentin ${ }^{1,3}$, Antoine Kimmoun $^{4,5}$, Bruno Levy ${ }^{4,5}$, \\ Duc Trung Nguyen ${ }^{6,7}$, Cécile Rumeau ${ }^{1,6}$ and Bruno Chenuel ${ }^{1,2 *}$
}

\begin{abstract}
'EA 3450 DevAH-Développement, Adaptation et Handicap, Régulations cardio-respiratoires et de la motricité, Université de Lorraine, Nancy, France, ${ }^{2}$ Explorations Fonctionnelles Respiratoires et de l'Aptitude à l'Exercice, Centre Universitaire de Médecine du Sport et Activité Physique Adaptée, CHRU-Nancy, Nancy, France, ${ }^{3}$ Département de Pneumologie, CHRU-Nancy, Nancy, France, " Médecine Intensive et Réanimation Brabois, CHRU-Nancy, Nancy, France, ${ }^{5}$ INSERM U1116, Université de Lorraine, Nancy, France, ${ }^{6}$ ORL et Chirurgie Cervico-Faciale, CHRU-Nancy, Nancy, France, ${ }^{7}$ INSERM U1254IADI, Université de Lorraine, Nancy, France
\end{abstract}

The growing coronavirus disease (COVID-19) crisis has stressed worldwide healthcare systems probably as never before, requiring a tremendous increase of the capacity of intensive care units to handle the sharp rise of patients in critical situation. Since the dominant respiratory feature of COVID-19 is worsening arterial hypoxemia, eventually leading to acute respiratory distress syndrome (ARDS) promptly needing mechanical ventilation, a systematic recourse to intubation of every hypoxemic patient may be difficult to sustain in such peculiar context and may not be deemed appropriate for all patients. Then, it is essential that caregivers have a solid knowledge of physiological principles to properly interpret arterial oxygenation, to intubate at the satisfactory moment, to adequately manage mechanical ventilation, and, finally, to initiate ventilator weaning, as safely and as expeditiously as possible, in order to make it available for the next patient. Through the expected mechanisms of COVID-19-induced hypoxemia, as well as the notion of silent hypoxemia often evoked in COVID-19 lung injury and its potential parallelism with high altitude pulmonary edema, from the description of hemoglobin oxygen affinity in patients with severe COVID-19 to the interest of the prone positioning in order to treat severe ARDS patients, this review aims to help caregivers from any specialty to handle respiratory support following recent knowledge in the pathophysiology of respiratory SARS-CoV-2 infection.

Keywords: coronavirus disease-19, respiratory physiology, control of breathing, hypoxemia, respiratory failure

\section{INTRODUCTION}

The growing coronavirus disease (COVID-19) crisis has stressed worldwide healthcare systems probably as never before, requiring a tremendous increase of the capacity of intensive care units to handle the sudden increase of patients in critical status. In many countries, innovative solutions have been found to change the routine hospital organization and cope with limited resources, leading to massive task-shifting with suspension of elective medical and surgical procedures and reassignment of volunteers (Aziz et al., 2020; Meschi et al., 2020; Xie et al., 2020b). If lung infection resulting from severe acute respiratory syndrome coronavirus 2 (SARS-CoV-2) has been shown to encompass various clinical features, the most serious presentation is worsening arterial 
hypoxemia, eventually leading to acute respiratory distress syndrome (ARDS) promptly needing mechanical ventilation (Guan et al., 2020; Wu and McGoogan, 2020). The systematic recourse to intubation of every patient suffering from hypoxemia may be difficult to sustain and may not be deemed appropriate for all patients. Then, it is essential that caregivers have solid knowledge of physiological principles to properly interpret arterial oxygenation, to intubate at the satisfactory moment, to adequately manage mechanical ventilation, and, finally, to begin weaning from the ventilator, as safely and as expeditiously as possible, in order to make it available for the next patient.

\section{COVID-19-RELATED HYPOXEMIA, INTERPRETATION OF BLOOD OXYGEN LEVELS, AND THE CONCEPT OF "SILENT HYPOXEMIA"}

\section{COVID-19-Related Hypoxemia and Suspected Physiopathological Mechanisms}

Hypoxemia is a defining feature of COVID-19. Viral respiratory infection has been shown to cause interstitial pneumonia, leading to a reduction in lung capacity and evolving in some patients to ARDS and respiratory failure. The typical imaging characteristics of COVID-19 pneumonia are non-specific, including peripheral ground-glass opacities with or without consolidation (Bernheim et al., 2020; Lang et al., 2020). They reflect diffuse alveolar injury associated to interstitial thickening, greatly altering gas exchange. In that context, four basic mechanisms of hypoxemia can be discussed: hypoventilation, diffusion impairment, shunt (i.e., hypoventilated areas of the lung are hyperemic), and ventilation-perfusion inequality. However, the most important cause by far is ventilation-perfusion mismatch, resulting from blood perfusing lung regions that have either limited or no ventilation [i.e., regions with low ventilation-perfusion ratios $\dot{V}_{\mathrm{A}} / \dot{Q}$ ratios) or intraparenchymal shunt, respectively], as Gattinoni et al. have reported in their cohort of COVID-19 patients with ARDS (Gattinoni et al., 2020c). They observed a shunt fraction around $\sim 0.5$ [i.e., venous to arterial shunt estimated by the shunted blood flow/total blood flow ratio $\left(\dot{Q}_{\mathrm{s}} / \dot{Q}_{\mathrm{T}}\right.$ ratio) of 50\%] and a large alveolar-to-arterial oxygen gradient $\left(\mathrm{P}_{\mathrm{A}} \mathrm{O}_{2}\right.$ $\mathrm{P}_{\mathrm{a}} \mathrm{O}_{2}$ gradient), enhanced by impaired hypoxic vasoconstriction (Gattinoni et al., 2020c). In addition, COVID-19 is often associated to coagulopathy, providing microemboli which could divert lung perfusion to regions with low $\dot{V}_{\mathrm{A}} / \dot{Q}$ ratios (Altemeier et al., 1998; Connors and Levy, 2020). Two major different phenotypes of COVID-19-associated ARDS have been described and probably involve different pathophysiological mechanisms: COVID-19 pneumonia type $\mathrm{L}$ depicted by high compliance (i.e., low elastance), low ventilation-to-perfusion ratio, and low recruitability, and COVID-19 pneumonia type $\mathrm{H}$ characterized by low compliance (i.e., high elastance), high right-to-left shunt (i.e., the hypoventilated areas of the lung are hyperemic), and high recruitability, analogous to what is experienced in common acute respiratory distress (Gattinoni et al., 2020a).
Therefore, in addition to the CT scan evaluation, the response to oxygen therapy can be helpful to distinguish the two phenotypes. The delivery of raised $\mathrm{FIO}_{2}$ would increase $\mathrm{PaO}_{2}$ and oxygen saturation in the L phenotype when ventilation-to-perfusion ratio mismatch drives hypoxia, avoiding or delaying the recourse to intubation and mechanical ventilation with satisfactory levels of arterial oxygenation by oxygen therapy. At the opposite, when hypoxia is mainly determined by a shunt, in $\mathrm{H}$ phenotype, a modest enhancement in oxygen saturation is expected by the delivery of high $\mathrm{FIO}_{2}$, often requiring earlier invasive ventilator assistance (Gattinoni et al., 2020a).

The underlying physiopathology has not been fully elucidated but partly due to the SARS-CoV-2 infecting the host recognizing the angiotensin-converting enzyme 2 (ACE-2) receptor as a specific target (Hoffmann et al., 2020; Lu et al., 2020). It is a membrane-bound aminopeptidase expressed on many human cells (respiratory tract, lung, heart, arteries, veins, kidney, and intestines; Hamming et al., 2004). More particularly, the ACE-2 receptor is located in alveolar epithelial cells and vascular endothelium, and when SARS-CoV-2 binds to it, a reduction in intracellular ACE-2 protein activity is provided, resulting in a marked immune response with hyperinflammatory syndrome and widespread endothelial dysfunction (Connors and Levy, 2020; Mehta et al., 2020; Polidoro et al., 2020; Zhang et al., 2020). Physiologically, ACE-2 is a vasodepressor, at the opposite of the homologous enzyme ACE-1 acting as a vasoconstrictor, and both proteins form the oxygen-sensitive renin-angiotensin system (Hampl et al., 2015). Histopathologically, recent works have emphasized the development of alveolar and interstitial exudative inflammation characterized by macrophage and monocyte predominance and associated to focal respiratory epithelial desquamation, hemorrhage, and type 2 pneumocyte proliferation (Tian et al., 2020; Xu et al., 2020).

Hypoxemia has been shown to be an independent prognostic factor for the severe form of COVID-19 (Wei et al., 2020) and associated with in-hospital mortality (Xie et al., 2020a).

\section{Interpretation of Blood Oxygenation From Pulse Oximetry, Caution, and Limits}

The assessment of oxygen saturation in the arterial blood by pulse oximetry should be carefully interpreted. Indeed pulse oximetry provides an estimate of the arterial oxygen saturation $\left(\mathrm{SpO}_{2}\right)$ and is not a direct measurement, as $\mathrm{CO}$-oximeters are able to do $\left(\mathrm{SaO}_{2}\right)$. By definition, oxygen saturation is the percentage of hemoglobin-binding sites occupied by oxygen, varying according to the arterial $\mathrm{PO}_{2}$, as stipulated by the oxyhemoglobin dissociation curve. The difference between the two methods is not negligible, reaching as much as $\pm 4 \%$ (Tobin, 1990).

The peculiar sigmoidal shape of the oxyhemoglobin dissociation curve involves several important features. In the higher range of partial pressures, the upper part of the curve is flat, impeding a significant decline in oxygen saturation when $\mathrm{PO}_{2}$ starts to drop. In contrast, the steeper portion of the dissociation curve markedly enhances the carriage of oxygen in the lungs (on-loading) and oxygen delivery to the tissues (off-loading). As lung injury progresses, leading to further impairment of gas exchange, $\mathrm{PO}_{2}$ may fall on the 
steep part of the dissociation curve (from 20 to $60 \mathrm{mmHg}$ ), allowing noticeable changes in the measured oxygen saturation with small changes in $\mathrm{PO}_{2}$. In this context, the natural variability of ventilation due to physiological acts as talking, laughing, or breath holding may change the alveolar $\mathrm{PO}_{2}$, thereby inducing similar variations in $\mathrm{PaO}_{2}$. Then, oxygen saturation monitoring should be observed for at least several minutes. Moreover, the position of the dissociation curve itself can be modified by the patient's acid-base status. Acidemia shifts it rightward and alkalemia in the opposite way. In the early course of COVID-19 pneumonia, numerous patients begin to hyperventilate in order to compensate for their collapsing $\mathrm{PaO}_{2}$. The hyperventilation consequently generates a respiratory alkalosis, shifting the dissociation curve to the left (increasing hemoglobin's oxygen affinity to facilitate oxygen loading) such that the predictable decrease in oxygen saturation with a falling $\mathrm{PaO}_{2}$ will be dampened and, in some cases, prevented (Hamilton et al., 2004). In addition, with respect to the alveolar gas equation, the decreased alveolar $\mathrm{CO}_{2}$ partial pressure $\left(\mathrm{PACO}_{2}\right)$ will lead to a comparable increase in alveolar oxygen partial pressure $\left(\mathrm{PAO}_{2}\right)$. These combined mechanisms are able to improve $\mathrm{SaO}_{2}$ in hypocapnic hypoxic stimulation compared with an isocapnic or hypercapnic hypoxia. In contrast, a right shift in oxygen dissociation (decreasing hemoglobin's oxygen affinity to facilitate oxygen unloading) is expected with fever, an obvious clinical feature in COVID19 , leading to noticeable desaturation without any change in the chemosensitive drive of breathing.

Some important practical limits of pulse oximetry also need to be known. Movements of the digits (shivering patient, for example), avoiding to identify an adequate pulse signal, or bright artificial light as observed in an operating room can induce false low readings (Schnapp and Cohen, 1990; Sinex, 1999).

The pulse oximeter uses two different wavelengths to estimate oxygen saturation, generated by two light-emitting diodes, but both wavelengths of light are similarly absorbed by hemoglobin in arterial blood, capillary, venous blood, and other soft tissues. Then, it is necessary to distinguish the pulsatile signal of arterial blood flow in order to limit the signal-to-noise ratio and dispense a valid result (Sinex, 1999). Therefore, factors that are able to limit pulsatile blood flow in the digits, such as hypotension and use of vasoconstrictor agent as well as the presence of peripheral vascular disease or Raynaud's phenomenon, may worsen the signal-to-noise ratio, resulting in an inaccurate estimation of arterial oxygen saturation. Chilblains have been increasingly recognized in association with COVID-19 (Bouaziz et al., 2020; Gottlieb and Long, 2020; Tosti et al., 2020), and peripheral vascular disease has been found to be associated with the usual comorbidities in patients suffering from severe COVID-19, such as diabetes and coronary artery disease (Du et al., 2020; Wu and McGoogan, 2020). It is also important to know that pulse oximeters dispense misleading results in front of either carboxyhemoglobinemia or methemoglobinemia since they are not able to distinguish these dyshemoglobinemias from oxygenated and deoxygenated hemoglobin. If carboxyhemoglobinemia is involved in heavy smokers or individuals using grills or heaters in enclosed spaces, it has been demonstrated that methemoglobinemia can result from the use of some drugs, including chloroquine (Rizvi et al., 2012).

Other important sources of artifact need to be cited, such as nail polish and increased skin pigmentation, especially if the real oxygen saturation is diminished (Bickler et al., 2005; Sutcu Cicek et al., 2011).

Furthermore, it has been demonstrated that large $\mathrm{SpO}_{2}$ to $\mathrm{SaO}_{2}$ differences exist in patients in critical condition with mediocre reproducibility of $\mathrm{SpO}_{2}$, specifically in shocked patients with low cardiac output or under high doses of vasopressor. In hemodynamically unstable patients, the detection limit of the sensor is most often exceeded (Van de Louw et al., 2001).

In addition to interpretation of blood oxygenation by pulse oximetry, to correctly assess the real efficacy of pulmonary gas exchange, it is required to know the fraction of inspired oxygen $\left(\mathrm{FIO}_{2}\right)$ in order to adequately calculate the $\mathrm{P}_{\mathrm{A}} \mathrm{O}_{2}-\mathrm{P}_{\mathrm{a}} \mathrm{O}_{2}$ gradient using the alveolar gas equation (cf. Figure 1). Then, if interpretation of blood oxygenation with supplemental oxygen is straightforward when a patient is breathing room air or is intubated, it is clearly problematic when a nasal cannula is used to deliver oxygen since the inspiratory fraction of oxygen is difficult to estimate. For example, depending on the effective patient's minute ventilation (more specifically tidal volume patient's demand), when a nasal cannula or a face mask is used to deliver pure oxygen flow rate at $21 / \mathrm{min}, \mathrm{FIO}_{2}$ can vary from 24 to $35 \%$ (Bazuaye et al., 1992). Therefore, the severity of hypoxemia cannot be assessed by the level of supplemental oxygen delivery. In practice, peculiar attention on the level of gas exchange impairment is recommended when high $\mathrm{F}_{\mathrm{i}} \mathrm{O}_{2}$ is used to treat hypoxemia according to a simple target level on pulse oximetry, given the flatness of the upper portion of the dissociation curve (Bickler et al., 2017).

A synthesis is proposed in Figure 2 in order to present a practical assessment of blood oxygenation using pulse oximetry and limitations.

\section{Concept of "Silent Hypoxemia"}

In one of the first largest studies on the clinical characteristics of coronavirus in China, shortness of breath has been reported in only $18.7 \%$ of 1,099 hospitalized patients with COVID-19 pneumonia, despite hypoxemia commonly requiring supplemental oxygen (41\%) and abnormal results on CT scans (86.2\%; Guan et al., 2020). Numerous reports worldwide have described a subset of patients with severe hypoxemia presenting no obvious respiratory difficulties or dyspnea, leading to abundant coverage in media with sensational headlines such as "happy hypoxia" or, more conventionally, "silent hypoxemia" (Couzin-Frankel, 2020; Levitan, 2020; Tobin et al., 2020b). However, in contrast to media's assertion, this questioning discrepancy is not really defying biology since fundamentals in respiratory physiology can account for most of it, with the specific effect of SARS-CoV-2 on control of breathing or chemoreceptors excepted.

Then, knowledge of the putative mechanisms involved in the genesis of dyspnea, basics of control of breathing, ventilatory response to hypoxia, and the role of $\mathrm{PCO}_{2}$ is necessary to address the mystery. 
Alveolar gas equation:

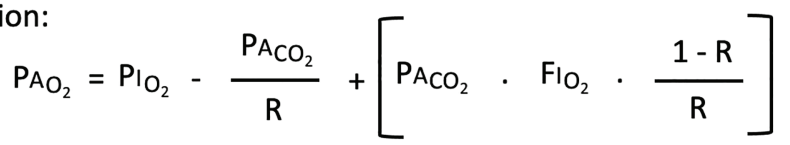

Where $\mathrm{PA}_{\mathrm{O} 2}=$ alveolar partial pressure of oxygen, $\mathrm{Pl}_{\mathrm{O} 2}=$ Inspired partial pressure of oxygen, $\mathrm{PA}_{\mathrm{CO}_{2}}=$ alveolar partial pressure of $\mathrm{CO}_{2}, \mathrm{Fl}_{\mathrm{O} 2}=$ inspired fraction of oxygen and $\mathrm{R}=$ respiratory exchange ratio ( from 0.7 to 1 ).

This is only valid if there is no $\mathrm{CO}_{2}$ in inspired gas.

The term in square brackets is relatively small and an estimation of $\mathrm{PA}_{\mathrm{O} 2}$ can be provided by the following equation:

$$
\mathrm{PAO}_{2}=\mathrm{P}_{\mathrm{O}_{2}}-\frac{\mathrm{PaCO}_{2}}{0.8}
$$

With $\mathrm{Pl}_{\mathrm{O}_{2}}=\mathrm{Fl}_{\mathrm{O} 2}$. $\left(\mathrm{Patm}-\mathrm{PH}_{2} \mathrm{O}\right) ; \mathrm{Patm}=$ atmospheric pressure , $\mathrm{PH}_{2} \mathrm{O}=$ water vapour pressure On room air ( $\mathrm{Fl}_{\mathrm{O} 2}=0.21$, or $21 \%$ ), at sea level ( $\mathrm{Patm}=760 \mathrm{mmHg}$ ) assuming $100 \%$ humidity in the alveoli $\left(\mathrm{PH}_{2} \mathrm{O}=47 \mathrm{mmHg}\right.$ at $\left.37^{\circ} \mathrm{C}\right)$.

Alveolar-arterial gradient of oxygen partial pressure:

$$
\mathrm{A}-\mathrm{a}\left(\mathrm{PO}_{2}\right)=\mathrm{PAO}_{2}-\mathrm{PaO}_{2}
$$

\begin{tabular}{|c|c|}
\hline Patient Measurements in practice & Main Conditions limiting PO accuracy \\
\hline $\begin{array}{l}\text { Patient at rest with quiet breathing if } \\
\text { possible }\end{array}$ & $\begin{array}{l}\text { Poor perfusion (hypotension, hypovolemic or } \\
\text { septic shock, cardiac failure...) }\end{array}$ \\
\hline $\begin{array}{l}\text { Use the index or middle finger (avoid } \\
\text { the ear lobe or toe) }\end{array}$ & $\begin{array}{l}\text { Dyshemoglobinemias (Carbon monoxide } \\
\text { poisoning, methemoglobinemia, fetal } \\
\text { hemoglobinemia) }\end{array}$ \\
\hline Remove fingernail polish if needed & $\begin{array}{l}\text { Dark pigmented skin (risk of overestimation of } \\
\text { oxygen saturation with values }<80 \% \text { ) }\end{array}$ \\
\hline Warm cold fingers & Sickle cell anemia (vasoocclusive crises) \\
\hline $\begin{array}{l}\text { Accept values only if the pulse signal is } \\
\text { strong }\end{array}$ & $\begin{array}{l}\text { Severe hyperbilirubinemia (> } 30 \mathrm{mg} / \mathrm{dL} \text {, due to } \\
\text { increased heme metabolism (hemolysis) or } \\
\text { decreased bilirubin metabolism (liver disease)) }\end{array}$ \\
\hline $\begin{array}{l}\text { Use the most common value on } \\
\text { readings for } 1 \text { to several minutes }\end{array}$ & $\begin{array}{l}\text { Some drugs (affecting oxygen's affinity for } \\
\text { hemoglobin) }\end{array}$ \\
\hline
\end{tabular}

FIGURE 1 | Useful toolkit to interpret oxygenation in an appropriate way.

FIGURE 2 | Blood oxygenation assessment with pulse oximetry (PO).

\section{Dyspnea and Control of Breathing}

Dyspnea is a highly multidimensional subjective experience needing careful assessment. It shows tremendous variability in regards to cultural and linguistic features and affective and cognitive factors (Anonymus, 1999; Parshall et al., 2012). The neurophysiologic mechanisms that give rise to the perception of dyspnea are incompletely understood, but the sensation of dyspnea probably results from a mismatch between efferent motor commands from the central nervous system (CNS) to the respiratory system and afferent sensory inputs (e.g., expected airflow, cage movements) from the respiratory system to the CNS (Adler and Janssens, 2019). It increases as inputs from receptors increase, and the central nervous system perceives that respiratory muscles cannot match the inputs and maintain adequate ventilation (Laviolette et al., 2014). 
Chemoreceptors are certainly involved in the sensation of dyspnea, rising respiratory output and subsequently activating respiratory afferences, associated to corollary discharges and direct projections from chemoreceptors to forebrain structures (notably the limbic system, also underlying the genesis of pain sensation; Banzett et al., 2000; Evans et al., 2002; Buchanan and Richerson, 2009). The insular cortex appears to play a crucial role since it has been demonstrated that insular lesions are associated with a blunted perception of dyspnea (Schon et al., 2008).

With the lung injury due to SARS-CoV-2, numerous sources of stimulation of sensory receptors may gather information and feed it to the central controller, from inflammation of the respiratory tract and lungs to hypoxemia, leading to dyspnea (Tobin, 2020). However, the experience of the subjective sensation of breathlessness is not systematic, depending on the patient and circumstances and with great similarity to pain sensation (Lansing et al., 2009).

\section{Ventilatory Response to Hypoxia and Dyspnea}

In healthy humans, the ventilatory response to partial pressure of arterial oxygen $\left(\mathrm{PaO}_{2}\right)$ is hyperbolic (Rebuck and Campbell, 1974). Reducing the partial pressure of arterial oxygen $\left(\mathrm{PaO}_{2}\right)$ from its normal value to $60 \mathrm{mmHg}$ has a marginal effect on pulmonary ventilation $\left(\dot{V}_{\mathrm{E}}\right)$ and $\mathrm{PaCO}_{2}$ (Forster and Dempsey, 1981). Nevertheless, further reducing $\mathrm{PaO}_{2}$, from about 60 to $30 \mathrm{mmHg}$, provides a progressive increase in $\dot{V}_{\mathrm{E}}$ following an exponential pattern (hyperbolic curve) and a decrease in $\mathrm{PaCO}_{2}$ (Forster and Dempsey, 1981). In contrast, the relationship between ventilation and arterial oxygen saturation $\left(\mathrm{SaO}_{2}\right)$ is linear (Rebuck and Campbell, 1974). Physiologically, in human subjects, the increase in ventilation occurs primarily because of a rise of tidal volume and only a small increase in the frequency of breathing (Reynolds and Milhorn, 1973; Bender et al., 1987). If tachypnea is one of the most important clinical indicators of respiratory distress, it could be without proportion to severe hypoxemia. Moreover, in COVID-19 patients, tachypnea would be more elicited by stimulation of lung receptors (pulmonary stretch, irritant, and J receptors) due to lung inflammation than by the hypoxic stimulus and therefore would not be the cornerstone of the intubation decision (Tobin, 2020).

It has been demonstrated that the level of hypoxia corresponding to the perception of air hunger in healthy subjects matches with the sharp increase of minute ventilation but far from all the subjects have complained as a strong increase in air hunger with a fall end-tidal oxygen partial pressure below $60 \mathrm{mmHg}$ (Moosavi et al., 2003). Dyspnea often occurs when $\mathrm{PaO}_{2}$ declines below $40 \mathrm{mmHg}$ (Manning and Schwartzstein, 1995). Like the large variability of the resting respiratory drive, there is a great between-subject and withinsubject variability of ventilatory response to hypoxia in healthy subjects (Sahn et al., 1977; Tobin et al., 1988; Matsuzawa et al., 1989). It has been demonstrated that the ventilatory response to hypoxia is decreased by half in elderly healthy people (Kronenberg and Drage, 1973; Peterson et al., 1981). The decrease is even more pronounced in patients suffering from diabetes (Nishimura et al., 1989; Weisbrod et al., 2005), who not only presented an impaired perception of sensory input from organs but also demonstrated an increased threshold for the perception of respiratory sensations has been (O'Donnell et al., 1988). Since diabetes is among the most frequently reported comorbidities and the median age is easily over 60 years in patients infected with COVID-19, it is not so surprising to observe numerous cases of "silent hypoxemia" (Grasselli et al., 2020; Huang et al., 2020; Richardson et al., 2020).

Furthermore, hypoxia is also well known to depress ventilation at the central nervous system level, possibly masking unpleasant sensations (Berry et al., 1989).

\section{Modulation of the Hypoxic Ventilatory Response by $\mathrm{CO}_{2}$}

In the absence of isocapnia, the ventilatory response to hypoxia is severely attenuated by hypocapnia associated with hyperventilation. This attenuation is due to an effect on the peripheral chemoreceptors (carotid body essentially) as well as to reduced drive from the central chemoreceptors (Lahiri and DeLaney, 1975; Fitzgerald and Dehghani, 1982; Moore et al., 1984). It has been demonstrated that moderate hypocapnia, corresponding to $\mathrm{PaCO}_{2}$ values from 5 to $10 \mathrm{mmHg}$ below eucapnia, flattened the hypoxic response, suggesting that a minimum level of $\mathrm{CO}_{2}$ is required to generate the hypoxic ventilatory response (Jounieaux et al., 2002; Corne et al., 2003; Wilson and Teppema, 2016). In order to elicit a valuable rise in ventilation, severe hypoxia must be associated to baseline $\mathrm{PaCO}_{2}$ that exceeds $39 \mathrm{mmHg}$ (Moosavi et al., 2003). Since hypoventilation is uncommon with COVID-19, hypoxemia accompanied by a normal alveolar-to-arterial oxygen gradient and increase in $\mathrm{PaCO}_{2}$ is highly unlikely, especially in the early phase of lung injury. In the great majority of severe cases, hypoxemia is accompanied by an increased alveolar-to-arterial oxygen gradient reflecting either ventilation-perfusion mismatch or intrapulmonary shunting and the compensatory ventilatory response to hypoxemia, leading to noticeable hypocapnia (Tobin, 2020).

Consequently, knowledge of the accompanying $\mathrm{PaCO}_{2}$ is imperative to assess the severity of the respiratory failure associated to hypoxemia, another reason to claim that isolated monitoring of $\mathrm{SaO}_{2}$ is insufficient to guide clinical decisions.

Taken together, it would not be so astonishing that many COVID-19 patients face hypoxemia and rapid respiratory failure without evidence of dyspnea.

\section{LESSONS FROM HIGH ALTITUDE AND AVIATION PHYSIOLOGY: ARE THE SIMILARITIES BETWEEN COVID-19 ARDS AND HIGH-ALTITUDE PULMONARY EDEMA RELEVANT?}

The common clinical pattern of COVID-19 lung injury is based upon a noticeable imbalance between relatively well-preserved lung compliance and a severely impaired pulmonary gas exchange, resulting in hypoxemia without corresponding signs of dyspnea or respiratory distress. Since the physiological characteristics of the hypocapnic ventilatory response to hypoxia have been extensively investigated in high altitude physiology and aviation 
medicine, learnings from them could be helpful in order to better manage the COVID-19 pandemic.

Beyond the apparent similarity between the COVID-19 silent hypoxemia and the non-lethal high altitude-induced hypoxemia associated to respiratory alkalosis, even allowing climbers to exercise in ascent despite very low levels of $\mathrm{PaO}_{2}$, some authors have advocated parallelism between COVID-19 acute respiratory distress syndrome and high-altitude pulmonary edema (HAPE), with great amplification via social media (Solaimanzadeh, 2020).

With the first descriptions of the clinical features of severe COVID-19 pneumonia, a debate has emerged on the development of typical ARDS or not, allowing specific and important clinical implications (Gattinoni et al., 2020b,c). Most of the patients with severe COVID-19 pneumonia meet the criteria that define internationally the ARDS [ARDS Berlin definition: acute onset of hypoxemia assessed by the $\mathrm{PaO}_{2} / \mathrm{FIO}_{2}$ ratio $\leq 300 \mathrm{mmHg}$ in a ventilated patient with a positive end-expiratory pressure (PEEP) of at least $5 \mathrm{cmH}_{2} \mathrm{O}$ and bilateral lung infiltrates not fully explained by heart failure or volume overload (Force et al., 2012)], but unusual presentations exist (Gattinoni et al., $2020 \mathrm{~b}, \mathrm{c})$. The main difference is relatively well-preserved lung mechanics with maintenance of a relatively high respiratory system compliance (close to the normal value of $50 \mathrm{ml} / \mathrm{cm}$ $\mathrm{H}_{2} \mathrm{O}$ ), in contrast to typical severe ARDS (Gattinoni et al., 2020 b,c). For some authors, the hypothesis for such hypoxemia associated to compliant lungs could be a hypoxic vasoconstriction (Gattinoni et al., 2020c). HAPE and ARDS are a non-cardiogenic form of pulmonary edema characterized by diffuse bilateral opacities on chest imaging caused by an imbalance in Starling forces, thus inducing fluid accumulation in the interstitial and alveolar spaces. However, the pathogenesis of such pulmonary edema is radically different between the two entities. HAPE is related to an excessive hypoxia-mediated increase in pulmonary vascular resistance or hypoxic pulmonary vasoconstriction increasing microvascular pressure and leading to a substantial increase in pulmonary artery pressure with overperfusion of some regions of the lung, elevated pulmonary capillary hydrostatic pressure, and leakage of fluid into the alveolar space (Swenson and Bartsch, 2012). Consequently, HAPE is a life-threatening condition that is favorably influenced (often reversed) by oxygen therapy, exposure to hyperbaric environment (using portable hyperbaric chambers), or descent/evacuation to lower altitude and, finally, very unusually needs intensive care (Swenson and Bartsch, 2012; Strapazzon et al., 2020). Since hypoxic vasoconstriction is the fundamental pathogenesis mechanism in HAPE, increasing the alveolar $\mathrm{PO}_{2}$ decreases pulmonary artery pressure, allowing the resolution of alveolar and interstitial edema and full recovery within hours to a few days of exposure. Distinctly, the underlying pathophysiological mechanisms in ARDS due to COVID-19 involve multi-organ viral-mediated inflammatory responses leading in the lung to genesis of alveolar epithelial inflammation and dysfunction of surfactant and alveolar fluid clearance, finally leading to alveolar collapse and/ or filling and marked ventilation-perfusion mismatch (Gattinoni et al., 2020a). Therefore, in marked contrast to HAPE, the delivery of supplemental oxygen in COVID-19 pneumonia may increase oxygen availability but will not be able to counteract the underlying inflammation or lung injury (Luks and Swenson, 2020; Strapazzon et al., 2020). This major distinction has crucial clinical implications since drugs well known to inhibit hypoxic pulmonary vasoconstriction-acetazolamide, systemic vasodilators like calcium channel blockers, or phosphodiesterase-5 inhibitors-are not only inappropriate but also expected to worsen ventilation/perfusion mismatch by raising prefusion blood flow to poorly and/or nonventilated lung regions, exacerbating hypoxemia and provoking hypotension in COVID-19 patients (Archer et al., 2020; Brugger et al., 2020; Luks and Swenson, 2020; Strapazzon et al., 2020).

\section{ON THE INTEREST OF PRONE POSITIONING IN COVID-19 PNEUMONIA, NOT ONLY TO IMPROVE GAS EXCHANGE BUT ALSO AS A STRATEGY TO DELAY OR AVOID MECHANICAL VENTILATION}

Prone positioning, i.e., when a patient is repositioned from supine position to lie on their front, has been used for more than 45 years to improve oxygenation in patients with acute respiratory failure and more specifically with ARDS (Guerin, 2014). Historically, in the 1970s, Mellins observed that children suffering from advanced cystic fibrosis spontaneously position themselves on their hands and knees to improve their ventilation, while Bryan hypothesized that, in acute respiratory failure with consequent impairment of functional residual capacity and enhancement of dependent airway closure, the prone position might recruit and stabilize the dependent lung (Bryan, 1974; Mellins, 1974). Since then, numerous randomized controlled trials and meta-analyses have demonstrated a conclusive and important mortality reduction using prone positioning early and for a prolonged time in subjects with severe ARDS (Abroug et al., 2008; Alsaghir and Martin, 2008; Guerin et al., 2013; Beitler et al., 2014; Hu et al., 2014; Lee et al., 2014; Bloomfield et al., 2015; Munshi et al., 2017). Nowadays, prone positioning is used not only as an efficient treatment in case of life-threatening hypoxemia but also in the prevention of ventilatory-induced lung injury (VILI; Chiumello and Brioni, 2016; Guerin, 2017; Mitchell and Seckel, 2018).

The main underlying physiologic mechanism for the ensuing improvement in patients' oxygenation with prone position is the decrease in intrapulmonary shunting, but an improvement of ventilatory mechanics is also involved (Gattinoni et al., 2013; Guerin et al., 2014). Prone positioning provides reduction in intrapulmonary shunt $\left(\dot{Q}_{s} / \dot{Q}_{T}\right)$, variation in lung ventilation $\left(\dot{V}_{\mathrm{A}}\right)$, and lung perfusion $(\dot{Q})$ distribution with improved $\dot{V}_{A} / \dot{Q}$ matching. By recruiting dorsal regions which have a larger number of alveolar units and by obtaining an increase in chest wall elastance, better ventilation to the perfused lung is provided, improving the ventilation/perfusion ratio and allowing a more homogeneous distribution of ventilation. This leads to a decrease in lung strain and, consecutively, reduction of VILI, reducing the risk of right heart failure (Gattinoni et al., 2013; Guerin et al., 2014; Ruste et al., 2018). The improvement of oxygenation in ARDS 
patients during a prone session is observed in $\sim 75 \%$ of the cases and sometimes intense (Guerin, 2014). The positive oxygenation response is commonly defined as an improvement in $\mathrm{PaO}_{2}$ by $20 \%$ or an increase in the $\mathrm{PaO}_{2} / \mathrm{FIO}_{2}$ ratio by $20 \mathrm{mmHg}$ (Guerin, 2014). It has been demonstrated that prone positioning reduced relative shunt fraction by about $30 \%$ and improved $\mathrm{PaO}_{2} / \mathrm{FIO}_{2}$ ratio by $34-62 \%$, with a variable temporal response (from an immediate response to a continued response for up to 24h; Kallet, 2015; Scholten et al., 2017).

Additional data are also important to note concerning the drainage of secretions which improves when prone, with material in the dorsal lung traveling more easily to open airways. Nevertheless, no significant reduction in the incidence of ventilator-associated pneumonia has been observed in a recent prospective study cohort of patients with severe ARDS (Ayzac et al., 2016). Major improvements in thoraco-abdominal compliance were particularly observed in patients with higher body mass index (Kallet, 2015).

During the COVID-19 pandemic, the use of prone positioning was proposed not only in ARDS patients requiring mechanical ventilation, as it is internationally recommended (Alhazzani et al., 2020; Wilson et al., 2020), but also in order to avoid or delay the recourse to intubation in the dramatic context of limited resources and capacity of intensive care units (Chad and Sampson, 2020; Elharrar et al., 2020; Sartini et al., 2020; Villarreal-Fernandez et al., 2020).

Innovative solutions have been found worldwide to cope with limited resources and to include the prone positioning in the management of patients requiring mechanical ventilation, even at the surge of the outbreak, resulting in the emergence of prone teams (Doussot et al., 2020; Kimmoun et al., 2020; Settembre et al., 2020).

In COVID-19 patients, the Surviving Sepsis campaign recommends a trial of prone positioning in mechanically ventilated patients who meet the moderate-to-severe ARDS definition (Alhazzani et al., 2020). Periods of 12-16h are suggested, based upon evidence for non-COVID ARDS (Alhazzani et al., 2020).

In conscious non-ventilated COVID-19 patients, it is expected that the underlying mechanism leading to an improvement in oxygenation is analogous, but only few studies evaluated the benefits of the prone position and no clear recommendations have emerged (Elharrar et al., 2020; Sartini et al., 2020). Shortterm improvements of oxygenation are observed in such patients, but further studies are needed to clarify the real benefit, particularly on mortality.

\section{PHYSIOLOGICAL BASIS FOR VENTILATORY SUPPORT}

If the initial message from the Chinese medical teams at the surge of the outbreak was to intubate early, the current ventilatory approach is to delay intubation if it clinically appears safe and feasible (Alhazzani et al., 2020). Currently, any therapy that could prevent intubation and mechanical ventilation (MV) or enhance MV weaning without further deterioration is welcome. Regrettably, "safe" lung-protective ventilation does not really exist; thus, ventilatory support needs to be individualized as the best compromise among respiratory mechanics, recruitability, gas exchange, and hemodynamics to minimize VILI and to ensure adequate oxygenation when arterial hypoxemia is refractory to oxygen therapy.

The spectrum of therapies and the different lung support which have been proposed to the management of ARDS with critical hypoxemia (i.e., severe ARDS, with $\mathrm{PaO}_{2} / \mathrm{FIO}_{2}$ $<100 \mathrm{mmHg}$ ) encompass the delivery of oxygen therapy by high-flow nasal cannula (HFNC) system and non-invasive positive pressure ventilation (NIPPV). In severe COVID-19 patients, these therapies should only be used in selected patients with hypoxemic respiratory failure and who are closely observed for early detection of further deterioration (Pfeifer et al., 2020).

With oxygen flow rates that can reach $60-80 \mathrm{~L}$ per minute, HFNC systems can more accordingly ensure the ventilatory demands of patients with respiratory distress and respiratory failure compared to the standard nasal cannula (Suffredini and Allison, 2020). They are able to reduce dead space, raise the end-expiratory lung volume, improve compliance, and reduce the work of breathing, resulting in improvement of pulmonary gas exchange (Suffredini and Allison, 2020). There is limited data to promote or refute the use of HFNC in SARS-CoV-2 and in ARDS patients; the failure rate has been found to be relatively high (Messika et al., 2015). However, it has been proposed to be combined with prone positioning (Colla et al., 2020; Suffredini and Allison, 2020; Villarreal-Fernandez et al., 2020). Decisions to continue HFNC treatment might depend on the results of periodic clinical assessments and repeated biological measurements corroborating clinical stability or improvement (Suffredini and Allison, 2020).

The use of NIPPV with a pressure support tailored to ensure a tidal volume between 7 and $10 \mathrm{ml} / \mathrm{kg}$ and a PEEP set between 2 and $10 \mathrm{~cm} \mathrm{H}_{2} \mathrm{O}$ could also lessen the intrapulmonary shunt and diminish the work of breathing, but just as the HFNC, NIPPV is associated with a high risk of failure and associated risks of a delayed start of invasive mechanical ventilation (Evans, 2001). The clinical result of the use of NIPPV needs to be carefully assessed, and if, following the first few hours, no significant improvement in pulmonary gas exchange is observed, it should be ceased and invasive mechanical ventilation should be initiated (Evans, 2001). More specifically, the magnitude of oxygenation disturbance is a predictor of NIPPV failure, and a $\mathrm{PaO}_{2} / \mathrm{FIO}_{2}$ ratio $<150 \mathrm{mmHg}$ is described as the decisive threshold for increased mortality (Bellani et al., 2017). However, some very recent works have emphasized the interest on non-invasive strategies in COVID-19, especially in order to avoid intubation (Brusasco et al., 2020; Oranger et al., 2020; Tobin et al., 2020a).

\section{Invasive Mechanical Ventilation}

The decision to intubate mainly relies on the clinical judgment of the critical care physician but is also based upon combined features such as level of hypoxemia, respiratory distress, increased work of breathing, fatigue, and gas exchange (Tobin, 2020). In the peculiar context of the COVID-19 pandemic, the most appropriate timing for the intubation of hypoxic patients with severe lung injury is not well known and also depends on the local capacity for mechanical ventilation. 
The main objective of mechanical ventilation is to lessen work and the oxygen cost of breathing, allowing oxygen stores to be redirected to vulnerable tissue beds (Tobin et al., 2012). In patients in acute respiratory distress, it has been demonstrated that the oxygen cost of breathing is enhanced to as much as $50 \%$ of total oxygen consumption (Field et al., 1984).

The basic principles of the assist-control ventilation are based upon the delivery of a breath under positive pressure provided by the ventilator, either triggered by the inspiratory effort achieved by the patient (pressure or flow triggered) or, independently, if such an effort is not performed within a preselected time period.

The main challenge for the physician then is to cycle the rhythm of the ventilator in synchrony with the patient's central respiratory rhythm while improving gas exchange. Three critical points have been identified: triggering (cycling on), post-trigger inflation, and inspiration-expiration switchover (cycling off; Tobin et al., 2012; Tobin, 2018).

The two most common modes used for mechanical ventilation are pressure-controlled ventilation (PCV), using a predetermined inflation pressure applied for a predetermined inflation time, and volume-controlled ventilation (VCV), using a predetermined volume.

With PCV, the delivered volume varies according to the properties of the respiratory system and also to the patient's effort and the inspiratory flow displays a decelerating shape; in VCV, the delivered volume is maintained constant, independently of the patient's effort, while the airway pressure is non-uniform and the inspiratory flow has a fixed shape.

It is important to note that the amount of active work performed by a patient in volume-cycled assist-control crucially relies on the sensitivity of the trigger and inspiratory flow settings. Despite optimal selected settings, it has been established that patients actively perform about a third of the work carried out by the ventilator during passive conditions (Marini et al., 1985). Pressure support can efficiently decrease the work of inspiration, but the level of inspiratory muscle unloading appears highly labile, with a coefficient of variation reaching up to 96\% among patients (Jubran et al., 1995).

If mechanical ventilation is a valid life-saving intervention, it can also enhance lung injury and, through VILI, contribute to multi-organ failure in patients with ARDS (Slutsky and Ranieri, 2013). The major determinant of VILI is the genesis of non-physiologic stress (tension) and strain (deformation), which relies not only on the size of the delivered tidal volume but also on the amount of lung resting volume (Gattinoni et al., 2012).

Therefore, the most common strategy to minimize VILI is low tidal volume $\left(V_{\mathrm{T}}\right)$ ventilation. A $V_{\mathrm{T}}$ from 4 to $8 \mathrm{ml} / \mathrm{kg}$ of predicted body weight is recommended in mechanically ventilated adults with COVID-19 and ARDS (Alhazzani et al., 2020). Along with low $V_{\mathrm{T}}$ ventilation, lower airway pressure use [i.e., plateau pressure $\left(P_{\text {plat }}\right) \leq 30 \mathrm{cmH}_{2} \mathrm{O}$ ] is a lung-protective strategy (Petrucci and De Feo, 2013).

\section{Ventilator Weaning}

Considering the side effects of mechanical ventilation and, additionally, the limitation of the intensive care resources during the COVID-19 pandemic, it is critical to get patients off the ventilator at the earliest possible time.
Since a delayed initiation of the weaning process has recurrently been observed, weaning predictor tests have been developed (Yang and Tobin, 1991; Tobin and Jubran, 2006). Among the physiological measurements that can alert a physician at initiating the weaning process, the level of rapid shallow breathing, quantified by frequency of breathing-to- $V_{\mathrm{T}}$ ratio $\left(\mathrm{fb} / V_{\mathrm{T}}\right)$, has been shown to be the best predictor of weaning outcome (Yang and Tobin, 1991; Tobin and Jubran, 2006). Synchronized mandatory ventilation is not recommended (Brochard et al., 1994).

Several approaches are used to manage weaning: from the use of a T-tube circuit allowing bouts of spontaneous breathing trials to the gradual reduction in the level of ventilator assistance (Tobin et al., 2012). Almost invariably, weaning failure arises within the first hour of attempted spontaneous breathing (Tobin, 2018).

\section{CONCLUSION}

In COVID-19 lung injury, as observed in many other respiratory diseases, control of breathing is the cornerstone of the clinical presentation, from dyspnea to respiratory failure, not only explaining symptoms but also allowing appropriate levels of physiological compensations in order to maintain efficient spontaneous ventilation. However, when overwhelmed, a patient critically requires ventilator assistance, which also greatly involves the key elements of the control of breathing.

A clear view of COVID-19-related hypoxemia needs an appropriate interpretation of blood oxygenation from pulse oximetry, keeping in mind cautions and limits of accuracy. The role of the position of the dissociation curve associated to changes of the patient's acid-base status or hyperventilationrelated hypocapnia, as well as the calculation of the $\mathrm{P}_{\mathrm{A}} \mathrm{O}_{2}-\mathrm{P}_{\mathrm{a}} \mathrm{O}_{2}$ gradient using the alveolar gas equation, is crucial to assess the real efficacy of pulmonary gas exchange. The participation of ventilatory response to hypoxia in the genesis of dyspnea and its modulation by $\mathrm{CO}_{2}$ can help to explain that many COVID-19 patients face hypoxemia and rapid respiratory failure without evidence of dyspnea.

When mechanical ventilation is decided in critical COVID-19 patients, the usual strategies to tailor it are involved, based upon the basis of respiratory physiology to lessen work and the oxygen cost of breathing. The safe discontinuation of mechanical ventilation needs a careful assessment of physiological parameters (level of rapid shallow breathing) in order to warn a physician that a ventilated patient might be able to come off the ventilator in order to make it available for the next patient in such a peculiar context of the COVID-19 pandemic.

\section{AUTHOR CONTRIBUTIONS}

EA, MP, AK, CR, and BC contributed to conception of this work: literature search, drafting, writing, and critical review of the text. SV, DN, and BL contributed to literature search, writing, and critical review of the final document. All authors contributed to the article and approved the submitted version. 


\section{REFERENCES}

Abroug, F., Ouanes-Besbes, L., Elatrous, S., and Brochard, L. (2008). The effect of prone positioning in acute respiratory distress syndrome or acute lung injury: a meta-analysis. Areas of uncertainty and recommendations for research. Intensive Care Med. 34, 1002-1011. doi: 10.1007/s00134-008-1062-3

Adler, D., and Janssens, J. P. (2019). The pathophysiology of respiratory failure: control of breathing, respiratory load, and muscle capacity. Respiration 97, 93-104. doi: 10.1159/000494063

Alhazzani, W., Moller, M. H., Arabi, Y. M., Loeb, M., Gong, M. N., Fan, E., et al. (2020). Surviving sepsis campaign: guidelines on the management of critically ill adults with coronavirus disease 2019 (COVID-19). Intensive Care Med. 46, 854-887. doi: 10.1007/s00134-020-06022-5

Alsaghir, A. H., and Martin, C. M. (2008). Effect of prone positioning in patients with acute respiratory distress syndrome: a meta-analysis. Crit. Care Med. 36, 603-609. doi: 10.1097/01.CCM.0000299739.98236.05

Altemeier, W. A., Robertson, H. T., Mckinney, S., and Glenny, R. W. (1998). Pulmonary embolization causes hypoxemia by redistributing regional blood flow without changing ventilation. J. Appl. Physiol. 85, 2337-2343. doi: 10.1152/jappl.1998.85.6.2337

Anonymus (1999). Dyspnea. Mechanisms, assessment, and management: a consensus statement. American Thoracic Society. Am. J. Respir. Crit. Care Med. 159, 321-340. doi: 10.1164/ajrccm.159.1.ats898

Archer, S. L., Sharp, W. W., and Weir, E. K. (2020). Differentiating COVID-19 pneumonia from acute respiratory distress syndrome and high altitude pulmonary edema: therapeutic implications. Circulation 142, 101-104. doi: 10.1161/CIRCULATIONAHA.120.047915

Ayzac, L., Girard, R., Baboi, L., Beuret, P., Rabilloud, M., Richard, J. C., et al. (2016). Ventilator-associated pneumonia in ARDS patients: the impact of prone positioning. A secondary analysis of the PROSEVA trial. Intensive Care Med. 42, 871-878. doi: 10.1007/s00134-015-4167-5

Aziz, S., Arabi, Y. M., Alhazzani, W., Evans, L., Citerio, G., Fischkoff, K., et al. (2020). Managing ICU surge during the COVID-19 crisis: rapid guidelines. Intensive Care Med. 46, 1303-1325. doi: 10.1007/s00134-020-06092-5

Banzett, R. B., Mulnier, H. E., Murphy, K., Rosen, S. D., Wise, R. J., and Adams, L. (2000). Breathlessness in humans activates insular cortex. Neuroreport 11, 2117-2120. doi: 10.1097/00001756-200007140-00012

Bazuaye, E. A., Stone, T. N., Corris, P. A., and Gibson, G. J. (1992). Variability of inspired oxygen concentration with nasal cannulas. Thorax 47, 609-611. doi: 10.1136/thx.47.8.609

Beitler, J. R., Shaefi, S., Montesi, S. B., Devlin, A., Loring, S. H., Talmor, D., et al. (2014). Prone positioning reduces mortality from acute respiratory distress syndrome in the low tidal volume era: a meta-analysis. Intensive Care Med. 40, 332-341. doi: 10.1007/s00134-013-3194-3

Bellani, G., Laffey, J. G., Pham, T., Madotto, F., Fan, E., Brochard, L., et al. (2017). Noninvasive ventilation of patients with acute respiratory distress syndrome. Insights from the LUNG SAFE study. Am. J. Respir. Crit. Care Med. 195, 67-77. doi: 10.1164/rccm.201606-1306OC

Bender, P. R., Weil, J. V., Reeves, J. T., and Moore, L. G. (1987). Breathing pattern in hypoxic exposures of varying duration. J. Appl. Physiol. 62, 640-645. doi: 10.1152/jappl.1987.62.2.640

Bernheim, A., Mei, X., Huang, M., Yang, Y., Fayad, Z. A., Zhang, N., et al. (2020). Chest CT findings in coronavirus disease-19 (COVID-19): relationship to duration of infection. Radiology 295:200463. doi: 10.1148/radiol.2020200463

Berry, D. T., Mcconnell, J. W., Phillips, B. A., Carswell, C. M., Lamb, D. G., and Prine, B. C. (1989). Isocapnic hypoxemia and neuropsychological functioning. J. Clin. Exp. Neuropsychol. 11, 241-251.

Bickler, P. E., Feiner, J. R., Lipnick, M. S., Batchelder, P., Macleod, D. B., and Severinghaus, J. W. (2017). Effects of acute, profound hypoxia on healthy humans: implications for safety of tests evaluating pulse oximetry or tissue oximetry performance. Anesth. Analg. 124, 146-153. doi: 10.1213/ ANE.0000000000001421

Bickler, P. E., Feiner, J. R., and Severinghaus, J. W. (2005). Effects of skin pigmentation on pulse oximeter accuracy at low saturation. Anesthesiology 102, 715-719. doi: 10.1097/00000542-200504000-00004

Bloomfield, R., Noble, D. W., and Sudlow, A. (2015). Prone position for acute respiratory failure in adults. Cochrane Database Syst. Rev. 2015:CD008095. doi: 10.1002/14651858.CD008095.pub2
Bouaziz, J. D., Duong, T., Jachiet, M., Velter, C., Lestang, P., Cassius, C., et al. (2020). Vascular skin symptoms in COVID-19: a french observational study. J Eur Acad Dermatol. Venereol. 34, e451-e452. doi: 10.1111/jdv.16544

Brochard, L., Rauss, A., Benito, S., Conti, G., Mancebo, J., Rekik, N., et al. (1994). Comparison of three methods of gradual withdrawal from ventilatory support during weaning from mechanical ventilation. Am. J. Respir. Crit. Care Med. 150, 896-903. doi: 10.1164/ajrccm.150.4.7921460

Brugger, H., Basnyat, B., Ellerton, J., Hefti, U., Strapazzon, G., and Zafren, K. (2020). Letter to the editor: COVID-19 lung injury is different from high altitude pulmonary edema. High Alt. Med. Biol. 21, 204-205. doi: 10.1089/ ham.2020.0061

Brusasco, C., Corradi, F., Di Domenico, A., Raggi, F., Timossi, G., Santori, G., et al. (2020). Continuous positive airway pressure in Covid-19 patients with moderate-to-severe respiratory failure. Eur. Respir. J. 8:2002524. doi: 10.1183/ 13993003.02524-2020

Bryan, A. C. (1974). Conference on the scientific basis of respiratory therapy. Pulmonary physiotherapy in the pediatric age group. Comments of a devil's advocate. Am. Rev. Respir. Dis. 110, 143-144. doi: 10.1164/arrd.1974.110.6P2.143

Buchanan, G. F., and Richerson, G. B. (2009). Role of chemoreceptors in mediating dyspnea. Respir. Physiol. Neurobiol. 167, 9-19. doi: 10.1016/j. resp.2008.12.002

Chad, T., and Sampson, C. (2020). Prone positioning in conscious patients on medical wards: a review of the evidence and its relevance to patients with COVID-19 infection. Clin. Med. 20, e97-e103. doi: 10.7861/clinmed.2020-0179

Chiumello, D., and Brioni, M. (2016). Severe hypoxemia: which strategy to choose. Crit. Care 20:132. doi: 10.1186/s13054-016-1304-7

Colla, J., Rodos, A., Seyller, H., and Weingart, S. (2020). Fighting COVID-19 hypoxia with one hand tied behind our back: blanket prohibition of highflow oxygen and noninvasive positive end-expiratory pressure in US hospitals. Ann. Emerg. Med. 75, 791-792. doi: 10.1016/j.annemergmed.2020.04.015

Connors, J. M., and Levy, J. H. (2020). COVID-19 and its implications for thrombosis and anticoagulation. Blood 135, 2033-2040. doi: 10.1182/ blood.2020006000

Corne, S., Webster, K., and Younes, M. (2003). Hypoxic respiratory response during acute stable hypocapnia. Am. J. Respir. Crit. Care Med. 167, 1193-1199. doi: $10.1164 / \mathrm{rccm} .2203019$

Couzin-Frankel, J. (2020). The mystery of the pandemic's 'happy hypoxia. Science 368, 455-456. doi: 10.1126/science.368.6490.455

Doussot, A., Ciceron, F., Cerutti, E., Salomon Du Mont, L., Thines, L., Capellier, G., et al. (2020). Prone positioning for severe acute respiratory distress syndrome in COVID-19 patients by a dedicated team: a safe and pragmatic reallocation of medical and surgical work force in response to the outbreak. Ann. Surg. 272, e311-e315. doi: 10.1097/SLA.0000000000004265

Du, Y., Tu, L., Zhu, P., Mu, M., Wang, R., Yang, P., et al. (2020). Clinical features of 85 fatal cases of COVID-19 from Wuhan. A retrospective observational study. Am. J. Respir. Crit. Care Med. 201, 1372-1379. doi: 10.1164/rccm.202003-0543OC

Elharrar, X., Trigui, Y., Dols, A. M., Touchon, F., Martinez, S., Prud'homme, E., et al. (2020). Use of prone positioning in nonintubated patients with COVID-19 and hypoxemic acute respiratory failure. JAMA 323, 2336-2338. doi: $10.1001 /$ jama.2020.8255

Evans, T. W. (2001). International consensus conferences in intensive care medicine: non-invasive positive pressure ventilation in acute respiratory failure. Organised jointly by the American Thoracic Society, the European Respiratory Society, the European Society of Intensive Care Medicine, and the Societe de reanimation de langue Francaise, and approved by the ATS Board of Directors, December 2000. Intensive Care Med. 27, 166-178. doi: $10.1007 / \mathrm{s} 001340000721$

Evans, K. C., Banzett, R. B., Adams, L., Mckay, L., Frackowiak, R. S., and Corfield, D. R. (2002). BOLD fMRI identifies limbic, paralimbic, and cerebellar activation during air hunger. J. Neurophysiol. 88, 1500-1511. doi: 10.1152/ jn.2002.88.3.1500

Field, S., Sanci, S., and Grassino, A. (1984). Respiratory muscle oxygen consumption estimated by the diaphragm pressure-time index. J. Appl. Physiol. Respir. Environ. Exerc. Physiol. 57, 44-51. doi: 10.1152/jappl.1984.57.1.44

Fitzgerald, R. S., and Dehghani, G. A. (1982). Neural responses of the cat carotid and aortic bodies to hypercapnia and hypoxia. J. Appl. Physiol. Respir. Environ. Exerc. Physiol. 52, 596-601. doi: 10.1152/jappl.1982.52.3.596 
Force, A. D. T., Ranieri, V. M., Rubenfeld, G. D., Thompson, B. T., Ferguson, N. D., Caldwell, E., et al. (2012). Acute respiratory distress syndrome: the Berlin definition. JAMA 307, 2526-2533. doi: 10.1001/jama.2012.5669

Forster, H. V., and Dempsey, J. A. (1981). "Ventilatory adaptations" in Lung biology in health and disease. Regulation of breathing. ed. T. Hornbein (New York: Dekker M), 845-904.

Gattinoni, L., Carlesso, E., and Caironi, P. (2012). Stress and strain within the lung. Curr. Opin. Crit. Care 18, 42-47. doi: 10.1097/MCC.0b013e32834f17d9

Gattinoni, L., Chiumello, D., Caironi, P., Busana, M., Romitti, F., Brazzi, L., et al. (2020a). COVID-19 pneumonia: different respiratory treatments for different phenotypes? Intensive Care Med. 46, 1099-1102. doi: 10.1007/ s00134-020-06033-2

Gattinoni, L., Chiumello, D., and Rossi, S. (2020b). COVID-19 pneumonia: ARDS or not? Crit. Care 24:154. doi: 10.1186/s13054-020-02880-z

Gattinoni, L., Coppola, S., Cressoni, M., Busana, M., Rossi, S., and Chiumello, D. (2020c). COVID-19 does not Lead to a "typical" acute respiratory distress syndrome. Am. J. Respir. Crit. Care Med. 201, 1299-1300. doi: 10.1164/ rccm.202003-0817LE

Gattinoni, L., Taccone, P., Carlesso, E., and Marini, J. J. (2013). Prone position in acute respiratory distress syndrome. Rationale, indications, and limits. Am. J. Respir. Crit. Care Med. 188, 1286-1293. doi: 10.1164/rccm.201308-1532CI

Gottlieb, M., and Long, B. (2020). Dermatologic manifestations and complications of COVID-19. Am. J. Emerg. Med. 38, 1715-1721. doi: 10.1016/j.ajem.2020.06.011

Grasselli, G., Zangrillo, A., Zanella, A., Antonelli, M., Cabrini, L., Castelli, A., et al. (2020). Baseline characteristics and outcomes of 1591 patients infected with SARS-CoV-2 admitted to ICUs of the lombardy region, Italy. JAMA 323, 1574-1581. doi: 10.1001/jama.2020.5394

Guan, W. J., Ni, Z. Y., Hu, Y., Liang, W. H., Ou, C. Q., He, J. X., et al. (2020). Clinical Characteristics of Coronavirus Disease 2019 in China. N. Engl. J. Med. 382, 1708-1720. doi: 10.1056/NEJMoa2002032

Guerin, C. (2014). Prone ventilation in acute respiratory distress syndrome. Eur. Respir. Rev. 23, 249-257. doi: 10.1183/09059180.00001114

Guerin, C. (2017). Prone positioning acute respiratory distress syndrome patients. Ann Transl Med 5:289. doi: 10.21037/atm.2017.06.63

Guerin, C., Baboi, L., and Richard, J. C. (2014). Mechanisms of the effects of prone positioning in acute respiratory distress syndrome. Intensive Care Med. 40, 1634-1642. doi: 10.1007/s00134-014-3500-8

Guerin, C., Reignier, J., Richard, J. C., Beuret, P., Gacouin, A., Boulain, T., et al. (2013). Prone positioning in severe acute respiratory distress syndrome. N. Engl. J. Med. 368, 2159-2168. doi: 10.1056/NEJMoa1214103

Hamilton, C., Steinlechner, B., Gruber, E., Simon, P., and Wollenek, G. (2004). The oxygen dissociation curve: quantifying the shift. Perfusion 19, 141-144. doi: 10.1191/0267659104pf734oa

Hamming, I., Timens, W., Bulthuis, M. L., Lely, A. T., Navis, G., and Van Goor, H. (2004). Tissue distribution of ACE2 protein, the functional receptor for SARS coronavirus. A first step in understanding SARS pathogenesis. J. Pathol. 203, 631-637. doi: 10.1002/path.1570

Hampl, V., Herget, J., Bibova, J., Banasova, A., Huskova, Z., Vanourkova, Z., et al. (2015). Intrapulmonary activation of the angiotensin-converting enzyme type 2/angiotensin 1-7/G-protein-coupled mas receptor axis attenuates pulmonary hypertension in Ren-2 transgenic rats exposed to chronic hypoxia. Physiol. Res. 64, 25-38. doi: 10.33549/physiolres.932861

Hoffmann, M., Kleine-Weber, H., Schroeder, S., Kruger, N., Herrler, T., Erichsen, S., et al. (2020). SARS-CoV-2 cell entry depends on ACE2 and TMPRSS2 and is blocked by a clinically proven protease inhibitor. Cell 181, 271.e8-280.e8. doi: 10.1016/j.cell.2020.02.052

Hu, S. L., He, H. L., Pan, C., Liu, A. R., Liu, S. Q., Liu, L., et al. (2014). The effect of prone positioning on mortality in patients with acute respiratory distress syndrome: a meta-analysis of randomized controlled trials. Crit. Care 18:R109. doi: 10.1186/cc13896

Huang, C., Wang, Y., Li, X., Ren, L., Zhao, J., Hu, Y., et al. (2020). Clinical features of patients infected with 2019 novel coronavirus in Wuhan, China. Lancet 395, 497-506. doi: 10.1016/S0140-6736(20)30183-5

Jounieaux, V., Parreira, V. F., Aubert, G., Dury, M., Delguste, P., and Rodenstein, D. O. (2002). Effects of hypocapnic hyperventilation on the response to hypoxia in normal subjects receiving intermittent positive-pressure ventilation. Chest 121, 1141-1148. doi: 10.1378/chest.121.4.1141

Jubran, A., Van De Graaff, W. B., and Tobin, M. J. (1995). Variability of patient-ventilator interaction with pressure support ventilation in patients with chronic obstructive pulmonary disease. Am. J. Respir. Crit. Care Med. 152, 129-136. doi: 10.1164/ajrccm.152.1.7599811

Kallet, R. H. (2015). A comprehensive review of prone position in ARDS. Respir. Care 60, 1660-1687. doi: 10.4187/respcare.04271

Kimmoun, A., Levy, B., and Chenuel, B. (2020). Usefulness and safety of a dedicated team to prone patients with severe ARDS due to COVID-19. Crit. Care 24:509. doi: 10.1186/s13054-020-03128-6

Kronenberg, R. S., and Drage, C. W. (1973). Attenuation of the ventilatory and heart rate responses to hypoxia and hypercapnia with aging in normal men. J. Clin. Invest. 52, 1812-1819.

Lahiri, S., and Delaney, R. G. (1975). Stimulus interaction in the responses of carotid body chemoreceptor single afferent fibers. Respir. Physiol. 24, 249-266. doi: 10.1016/0034-5687(75)90017-1

Lang, M., Som, A., Mendoza, D. P., Flores, E. J., Reid, N., Carey, D., et al. (2020). Hypoxaemia related to COVID-19: vascular and perfusion abnormalities on dual-energy CT. Lancet Infect. Dis. 20, 1365-1366. doi: 10.1016/ S1473-3099(20)30367-4

Lansing, R. W., Gracely, R. H., and Banzett, R. B. (2009). The multiple dimensions of dyspnea: review and hypotheses. Respir. Physiol. Neurobiol. 167, 53-60. doi: 10.1016/j.resp.2008.07.012

Laviolette, L., Laveneziana, P., and Faculty, E. R. S. R. S. (2014). Dyspnoea: a multidimensional and multidisciplinary approach. Eur. Respir. J. 43, 1750-1762. doi: 10.1183/09031936.00092613

Lee, J. M., Bae, W., Lee, Y. J., and Cho, Y. J. (2014). The efficacy and safety of prone positional ventilation in acute respiratory distress syndrome: updated study-level meta-analysis of 11 randomized controlled trials. Crit. Care Med. 42, 1252-1262. doi: 10.1097/CCM.0000000000000122

Levitan, R. (2020). The infection that's silently killing coronavirus patients. The New York Times, April 20.

Lu, R., Zhao, X., Li, J., Niu, P., Yang, B., Wu, H., et al. (2020). Genomic characterisation and epidemiology of 2019 novel coronavirus: implications for virus origins and receptor binding. Lancet 395, 565-574. doi: 10.1016/ S0140-6736(20)30251-8

Luks, A. M., and Swenson, E. R. (2020). COVID-19 lung injury and highaltitude pulmonary edema. A false equation with dangerous implications. Ann. Am. Thorac. Soc. 17, 918-921. doi: 10.1513/AnnalsATS.202004-327FR

Manning, H. L., and Schwartzstein, R. M. (1995). Pathophysiology of dyspnea. N. Engl. J. Med. 333, 1547-1553. doi: 10.1056/NEJM199512073332307

Marini, J. J., Capps, J. S., and Culver, B. H. (1985). The inspiratory work of breathing during assisted mechanical ventilation. Chest 87, 612-618. doi: 10.1378/chest.87.5.612

Matsuzawa, Y., Fujimoto, K., Kobayashi, T., Namushi, N. R., Harada, K., Kohno, H., et al. (1989). Blunted hypoxic ventilatory drive in subjects susceptible to high-altitude pulmonary edema. J. Appl. Physiol. 66, 1152-1157. doi: 10.1152/jappl.1989.66.3.1152

Mehta, P., Mcauley, D. F., Brown, M., Sanchez, E., Tattersall, R. S., Manson, J. J., et al. (2020). COVID-19: consider cytokine storm syndromes and immunosuppression. Lancet 395, 1033-1034. doi: 10.1016/S0140-6736(20)30628-0

Mellins, R. B. (1974). Pulmonary physiotherapy in the pediatric age group. Am. Rev. Respir. Dis. 110, 137-142. doi: 10.1164/arrd.1974.110.6P2.137

Meschi, T., Rossi, S., Volpi, A., Ferrari, C., Sverzellati, N., Brianti, E., et al. (2020). Reorganization of a large academic hospital to face COVID-19 outbreak: the model of Parma, Emilia-Romagna region, Italy. Eur. J. Clin. Investig. 50:e13250. doi: 10.1111/eci.13250

Messika, J., Ben Ahmed, K., Gaudry, S., Miguel-Montanes, R., Rafat, C., Sztrymf, B., et al. (2015). Use of high-flow nasal cannula oxygen therapy in subjects with ARDS: a 1-year observational study. Respir. Care 60, 162-169. doi: 10.4187/respcare.03423

Mitchell, D. A., and Seckel, M. A. (2018). Acute respiratory distress syndrome and prone positioning. AACN Adv. Crit. Care 29, 415-425. doi: 10.4037/ aacnacc 2018161

Moore, L. G., Huang, S. Y., Mccullough, R. E., Sampson, J. B., Maher, J. T., Weil, J. V., et al. (1984). Variable inhibition by falling CO2 of hypoxic ventilatory response in humans. J. Appl. Physiol. Respir. Environ. Exerc. Physiol. 56, 207-210. doi: 10.1152/jappl.1984.56.1.207

Moosavi, S. H., Golestanian, E., Binks, A. P., Lansing, R. W., Brown, R., and Banzett, R. B. (2003). Hypoxic and hypercapnic drives to breathe generate equivalent levels of air hunger in humans. J. Appl. Physiol. 94, 141-154. doi: 10.1152/japplphysiol.00594.2002 
Munshi, L., Del Sorbo, L., Adhikari, N. K. J., Hodgson, C. L., Wunsch, H., Meade, M. O., et al. (2017). Prone position for acute respiratory distress syndrome. A systematic review and meta-analysis. Ann. Am. Thorac. Soc. 14, S280-S288. doi: 10.1513/AnnalsATS.201704-343OT

Nishimura, M., Miyamoto, K., Suzuki, A., Yamamoto, H., Tsuji, M., Kishi, F., et al. (1989). Ventilatory and heart rate responses to hypoxia and hypercapnia in patients with diabetes mellitus. Thorax 44, 251-257. doi: 10.1136/thx.44.4.251

O’Donnell, C. R., Friedman, L. S., Russomanno, J. H., and Rose, R. M. (1988). Diminished perception of inspiratory-resistive loads in insulin-dependent diabetics. N. Engl. J. Med. 319, 1369-1373. doi: 10.1056/NEJM198811243192102

Oranger, M., Gonzalez-Bermejo, J., Dacosta-Noble, P., Llontop, C., Guerder, A., Trosini-Desert, V., et al. (2020). Continuous positive airway pressure to avoid intubation in SARS-CoV-2 pneumonia: a two-period retrospective case-control study. Eur. Respir. J. 56:2001692. doi: 10.1183/13993003.01692-2020

Parshall, M. B., Schwartzstein, R. M., Adams, L., Banzett, R. B., Manning, H. L., Bourbeau, J., et al. (2012). An official American Thoracic Society statement: update on the mechanisms, assessment, and management of dyspnea. Am. J. Respir. Crit. Care Med. 185, 435-452. doi: 10.1164/rccm.201111-2042ST

Peterson, D. D., Pack, A. I., Silage, D. A., and Fishman, A. P. (1981). Effects of aging on ventilatory and occlusion pressure responses to hypoxia and hypercapnia. Am. Rev. Respir. Dis. 124, 387-391. doi: 10.1164/arrd.1981.124.4.387

Petrucci, N., and De Feo, C. (2013). Lung protective ventilation strategy for the acute respiratory distress syndrome. Cochrane Database Syst. Rev. 2013: CD003844. doi: 10.1002/14651858.CD003844.pub4

Pfeifer, M., Ewig, S., Voshaar, T., Randerath, W. J., Bauer, T., Geiseler, J., et al. (2020). Position paper for the state-of-the-art application of respiratory support in patients with COVID-19. Respiration 99, 521-542. doi: $10.1159 / 000509104$

Polidoro, R. B., Hagan, R. S., De Santis Santiago, R., and Schmidt, N. W. (2020). Overview: systemic inflammatory response derived from lung injury caused by SARS-CoV-2 infection explains severe outcomes in COVID-19. Front. Immunol. 11:1626. doi: 10.3389/fimmu.2020.01626

Rebuck, A. S., and Campbell, E. J. (1974). A clinical method for assessing the ventilatory response to hypoxia. Am. Rev. Respir. Dis. 109, 345-350. doi: 10.1164/arrd.1974.109.3.345

Reynolds, W. J., and Milhorn, H. T. Jr. (1973). Transient ventilatory response to hypoxia with and without controlled alveolar PCO2. J. Appl. Physiol. 35, 187-196. doi: 10.1152/jappl.1973.35.2.187

Richardson, S., Hirsch, J. S., Narasimhan, M., Crawford, J. M., Mcginn, T., Davidson, K. W., et al. (2020). Presenting characteristics, comorbidities, and outcomes among 5700 patients hospitalized with COVID-19 in the new York City area. JAMA 323, 2052-2059. doi: 10.1001/jama.2020.6775

Rizvi, I., Zaman, S., Zaidi, N., Asif, M. S., and Abdali, N. (2012). Acute lifethreatening methaemoglobinaemia following ingestion of chloroquine. $B M J$ Case Rep. 2012:bcr1220115383. doi: 10.1136/bcr.12.2011.5383

Ruste, M., Bitker, L., Yonis, H., Riad, Z., Louf-Durier, A., Lissonde, F., et al. (2018). Hemodynamic effects of extended prone position sessions in ARDS. Ann. Intensive Care 8:120. doi: 10.1186/s13613-018-0464-9

Sahn, S. A., Zwillich, C. W., Dick, N., Mccullough, R. E., Lakshminarayan, S., and Weil, J. V. (1977). Variability of ventilatory responses to hypoxia and hypercapnia. J. Appl. Physiol. Respir. Environ. Exerc. Physiol. 43, 1019-1025. doi: 10.1152/jappl.1977.43.6.1019

Sartini, C., Tresoldi, M., Scarpellini, P., Tettamanti, A., Carcò, F., Landoni, G., et al. (2020). Respiratory parameters in patients with COVID-19 after using noninvasive ventilation in the prone position outside the intensive care unit. JAMA 323, 2338-2340. doi: 10.1001/jama.2020.7861

Schnapp, L. M., and Cohen, N. H. (1990). Pulse oximetry. Uses and abuses. Chest 98, 1244-1250.

Scholten, E. L., Beitler, J. R., Prisk, G. K., and Malhotra, A. (2017). Treatment of ARDS with prone positioning. Chest 151, 215-224. doi: 10.1016/j. chest.2016.06.032

Schon, D., Rosenkranz, M., Regelsberger, J., Dahme, B., Buchel, C., and Von Leupoldt, A. (2008). Reduced perception of dyspnea and pain after right insular cortex lesions. Am. J. Respir. Crit. Care Med. 178, 1173-1179. doi: 10.1164/rccm.200805-731OC

Settembre, N., Maurice, P., Paysant, J., Theurel, J., Claudon, L., Kimmoun, A., et al. (2020). The use of exoskeletons to help with prone positioning in the intensive care unit during COVID-19. Ann. Phys. Rehabil. Med. 63, 379-382. doi: 10.1016/j.rehab.2020.05.004
Sinex, J. E. (1999). Pulse oximetry: principles and limitations. Am. J. Emerg. Med. 17, 59-67. doi: 10.1016/S0735-6757(99)90019-0

Slutsky, A. S., and Ranieri, V. M. (2013). Ventilator-induced lung injury. N. Engl. J. Med. 369, 2126-2136. doi: 10.1056/NEJMra1208707

Solaimanzadeh, I. (2020). Acetazolamide, Nifedipine Phosphodiesterase inhibitors: rationale for their utilization as adjunctive countermeasures in the treatment of coronavirus disease 2019 (COVID-19). Cureus 12:e7343. doi: 10.7759/ cureus. 7343

Strapazzon, G., Hilty, M. P., Bouzat, P., Pratali, L., Brugger, H., and Rauch, S. (2020). To compare the incomparable: COVID-19 pneumonia and highaltitude disease. Eur. Respir. J. 55:2001362. doi: 10.1183/13993003.01362-2020

Suffredini, D. A., and Allison, M. G. (2020). A rationale for use of high flow nasal cannula for select patients with suspected or confirmed severe acute respiratory syndrome Coronavirus-2 infection. J. Intensive Care Med. 36, 9-17. doi: $10.1177 / 0885066620956630$

Sutcu Cicek, H., Gumus, S., Deniz, O., Yildiz, S., Acikel, C. H., Cakir, E., et al. (2011). Effect of nail polish and henna on oxygen saturation determined by pulse oximetry in healthy young adult females. Emerg. Med. J. 28, 783-785. doi: 10.1136/emj.2010.096073

Swenson, E. R., and Bartsch, P. (2012). High-altitude pulmonary edema. Compr. Physiol. 2, 2753-2773. doi: 10.1002/cphy.c100029

Tian, S., Hu, W., Niu, L., Liu, H., Xu, H., and Xiao, S. Y. (2020). Pulmonary pathology of early-phase 2019 novel coronavirus (COVID-19) pneumonia in two patients with lung cancer. J. Thorac. Oncol. 15, 700-704. doi: 10.1016/j.jtho.2020.02.010

Tobin, M. J. (1990). Respiratory monitoring. JAMA 264, 244-251. doi: 10.1001/ jama.1990.03450020096034

Tobin, M. J. (2018). Physiologic basis of mechanical ventilation. Ann. Am. Thorac. Soc. 15, S49-S52. doi: 10.1513/AnnalsATS.201705-417KV

Tobin, M. J. (2020). Basing respiratory management of COVID-19 on physiological principles. Am. J. Respir. Crit. Care Med. 201, 1319-1320. doi: 10.1164/ rccm.202004-1076ED

Tobin, M. J., and Jubran, A. (2006). Variable performance of weaning-predictor tests: role of Bayes' theorem and spectrum and test-referral bias. Intensive Care Med. 32, 2002-2012. doi: 10.1007/s00134-006-0439-4

Tobin, M. J., Jubran, A., and Laghi, F. (2020a). Noninvasive strategies in COVID-19: epistemology, randomised trials, guidelines, physiology. Eur. Respir. J. doi: 10.1183/13993003.04247-2020 [Epub ahead of print]

Tobin, M. J., Laghi, F., and Jubran, A. (2012). Ventilatory failure, ventilator support, and ventilator weaning. Compr. Physiol. 2, 2871-2921. doi: 10.1002/cphy.c110030

Tobin, M. J., Laghi, F., and Jubran, A. (2020b). Why COVID-19 silent hypoxemia is baffling to physicians. Am. J. Respir. Crit. Care Med. 202, 356-360. doi: 10.1164/rccm.202006-2157CP

Tobin, M. J., Mador, M. J., Guenther, S. M., Lodato, R. F., and Sackner, M. A. (1988). Variability of resting respiratory drive and timing in healthy subjects. J. Appl. Physiol. 65, 309-317. doi: 10.1152/jappl.1988.65.1.309

Tosti, G., Barisani, A., Queirolo, P., Pennacchioli, E., Villa, L., Lodeserto, A. M., et al. (2020). Skin signs resembling vascular acrosyndromes during the COVID-19 outbreak in Italy. Clin. Exp. Dermatol. 45, 757-758. doi: 10.1111/ced.14267

Van De Louw, A., Cracco, C., Cerf, C., Harf, A., Duvaldestin, P., Lemaire, F., et al. (2001). Accuracy of pulse oximetry in the intensive care unit. Intensive Care Med. 27, 1606-1613. doi: 10.1007/s001340101064

Villarreal-Fernandez, E., Patel, R., Golamari, R., Khalid, M., Dewaters, A., and Haouzi, P. (2020). A plea for avoiding systematic intubation in severely hypoxemic patients with COVID-19-associated respiratory failure. Crit. Care 24:337. doi: 10.1186/s13054-020-03063-6

Wei, Y. Y., Wang, R. R., Zhang, D. W., Tu, Y. H., Chen, C. S., Ji, S., et al. (2020). Risk factors for severe COVID-19: evidence from 167 hospitalized patients in Anhui, China. J. Infect. 81, e89-e92. doi: 10.1016/j.jinf.2020.04.010

Weisbrod, C. J., Eastwood, P. R., O'driscoll, G., and Green, D. J. (2005). Abnormal ventilatory responses to hypoxia in type 2 diabetes. Diabet. Med. 22, 563-568. doi: $10.1111 / j .1464-5491.2005 .01458 . x$

Wilson, K. C., Chotirmall, S. H., Bai, C., and Rello, J. (2020). COVID-19: Interim Guidance on Management Pending Empirical Evidence. From an American Thoracic Society-led International Task Force: A.T. Society; on behalf of the International Task Force on COVID-19. Available at: https:// www.thoracic.org/covid/covid-19-guidance.pdf (Accessed May 9, 2020).

Wilson, R. J., and Teppema, L. J. (2016). Integration of central and peripheral respiratory Chemoreflexes. Compr. Physiol. 6, 1005-1041. doi: 10.1002/cphy. c140040 
Wu, Z., and Mcgoogan, J. M. (2020). Characteristics of and important Lessons from the coronavirus disease 2019 (COVID-19) outbreak in China: summary of a report of 72314 cases from the Chinese Center for Disease Control and Prevention. JAMA 323, 1239-1242. doi: 10.1001/jama.2020.2648

Xie, J., Covassin, N., Fan, Z., Singh, P., Gao, W., Li, G., et al. (2020a). Association between hypoxemia and mortality in patients with COVID-19. Mayo Clin. Proc. 95, 1138-1147. doi: 10.1016/j.mayocp.2020.04.006

Xie, J., Tong, Z., Guan, X., Du, B., Qiu, H., and Slutsky, A. S. (2020b). Critical care crisis and some recommendations during the COVID-19 epidemic in China. Intensive Care Med. 46, 837-840. doi: 10.1007/s00134-020-05979-7

Xu, Z., Shi, L., Wang, Y., Zhang, J., Huang, L., Zhang, C., et al. (2020). Pathological findings of COVID-19 associated with acute respiratory distress syndrome. Lancet Respir. Med. 8, 420-422. doi: 10.1056/NEJM199105233242101

Yang, K. L., and Tobin, M. J. (1991). A prospective study of indexes predicting the outcome of trials of weaning from mechanical ventilation. N. Engl. J. Med. 324, 1445-1450. doi: 10.1056/NEJM199105233242101
Zhang, H., Penninger, J. M., Li, Y., Zhong, N., and Slutsky, A. S. (2020). Angiotensin-converting enzyme 2 (ACE2) as a SARS-CoV-2 receptor: molecular mechanisms and potential therapeutic target. Intensive Care Med. 46, 586-590. doi: $10.1007 / \mathrm{s} 00134-020-05985-9$

Conflict of Interest: The authors declare that the research was conducted in the absence of any commercial or financial relationships that could be construed as a potential conflict of interest.

Copyright (C) 2021 Allado, Poussel, Valentin, Kimmoun, Levy, Nguyen, Rumeau and Chenuel. This is an open-access article distributed under the terms of the Creative Commons Attribution License (CC BY). The use, distribution or reproduction in other forums is permitted, provided the original author(s) and the copyright owner(s) are credited and that the original publication in this journal is cited, in accordance with accepted academic practice. No use, distribution or reproduction is permitted which does not comply with these terms. 